\title{
Digestibilidade de dietas e balanços metabólicos de suínos alimentados com dietas contendo aflatoxinas
}

\author{
Diets digestibility and metabolic balances of pigs fed diets containing aflatoxins
}

\author{
Luciano Hauschild ${ }^{1}$ Paulo Alberto Lovatto ${ }^{1}$ Marco Antônio Kunrath ${ }^{1}$ \\ Amanda d'Ávila Carvalho' ${ }^{1}$ Gerson Guarez Garcia' \\ Carlos Augusto Mallmann²
}

\section{RESUMO}

Um experimento foi realizado para avaliar a digestibilidade de dietas e balanços metabólicos de suínos alimentados com dietas contendo $800 \mathrm{ug} \mathrm{kg}^{-1}$ de aflatoxinas. Foram utilizados oito suínos, meio-irmãos, com peso médio inicial de $13 \mathrm{~kg}$, alojados em gaiolas metabólicas, em ambiente semi-climatizado. $O$ delineamento experimental foi inteiramente casualizado, com dois tratamentos (dieta controle e controle $+800 \mathrm{ug} \mathrm{kg}^{-1}$ de aflatoxinas) e quatro repetições, sendo o animal a unidade experimental. Os coeficientes de digestibilidade da matéria seca, proteína e energia bruta não foram influenciados $(P>0,05)$ pela adição de $800 \mathrm{ug} \mathrm{kg}^{-1}$ de aflatoxinas na dieta. A metabolização da energia bruta foi $6 \%$ superior $(P<0,05)$ quando comparada à dieta controle. A excreção urinária de $N$ aumentou $(P<0,05)$ em $52 \%$ e a retenção relativa à absorção diminuiu $(P<0,05)$ em $31 \%$ nos animais alimentados com a dieta contendo aflatoxinas. No balanço energético, a energia bruta ingerida não foi influenciada $(P>0,05)$ pela adição de aflatoxinas. A excreção urinária de energia aumentou $(P<0,05) 52 \%$ nos animais alimentados com a dieta contendo aflatoxinas. A presença de $800 \mathrm{ug}^{-1}$ de aflatoxinas na dieta não afetou a digestibilidade, mas alterou o metabolismo protéico e energético de leitões.

Palavras-chave: coeficiente de digestibilidade, balanço do nitrogênio, metabolismo energético.

\section{ABSTRACT}

An experiment was conducted in order to investigate the digestibility of diets and metabolic balances of piglets fed diets containing $800 \mathrm{ug} \mathrm{kg}^{-1}$ of aflatoxins. This study used eight with littermate barrows whith an average initial weight of $13 \mathrm{~kg}$, housed in metabolic cages in a semi-acclimatized environment. A completely randomized experimental design was used, with two treatments (control diet and control $+800 \mathrm{ug}^{-1}$ of aflatoxins) and four replications, with the animal as the experimental unit. The digestibility coefficients of dry matter, protein and gross energy were not affected $(P>0.05)$ by the addition of $800 \mathrm{ug} \mathrm{kg}^{-1}$ of aflatoxins in the diet. The gross energy metabolization was $6 \%(P<0.05)$ higher when compared to the control diet. The $N$ urinary losses increased $(P<0.05) 52 \%$ and the retention related to absorption decreased $(P<0.05)$ $31 \%$ in piglets fed diet containing aflatoxins. Concerning the energy balance, the gross energy digested was not influenced $(P>0.05)$ by the addition of aflatoxins in the diet. Energy losses in urine increased $(P<0.05) 52 \%$ in the pigs fed diets containing aflatoxins. The presence of an aflatoxin level of $800 \mathrm{ug} \mathrm{kg}^{-1}$ in the diet did not affect the digestibility, but it altered the protein and energy metabolism of weaned piglets.

Key words: digestibility coefficient, nitrogen balance, energy metabolism.

\section{INTRODUÇÃO}

A produção anual de milho no Brasil é de cerca de 40 milhões de toneladas (AGRIANUAL, 2005), sendo 28\% dessa produção utilizada pela suinocultura (SINDIRAÇÕES, 2004). O milho é cultivado em áreas de clima tropical e subtropical, com temperaturas e umidades variáveis, que propiciam o crescimento de diversos fungos produtores de micotoxinas (DILKIN et al., 2003). As perdas de milho devidas aos fungos podem atingir 25\% da produção de milho (PEDROSA \& DEZEN, 1991). Entre as micotoxinas, as aflatoxinas têm apresentado uma ocorrência média de 35\% no milho produzido no Estado do Rio Grande do Sul (HENNING \& DICK, 1995).

${ }^{1}$ Departamento de Zootecnia, UFSM, 97105-900, Santa Maria, RS, Brasil. E-mail: lovatto@smail.ufsm.br. Autor para correspondência.

${ }^{2}$ Departamento de Medicina Veterinária Preventiva, Laboratório de análises micotoxicológicas, UFSM, Santa Maria, RS, Brasil 
As aflatoxinas são metabólitos fúngicos secundários, produzidos por Aspergillus flavus e Aspergillus parasiticus durante o cultivo e no armazenamento de cereais. Temperaturas de 25 a $35^{\circ} \mathrm{C}$, umidade do substrato acima de $14 \%$ e grãos danificados favorecem o desenvolvimento de fungos produtores de micotoxinas (JACOBSEN et al., 1993). Vários nutrientes são importantes para o desenvolvimento fúngico, sobretudo o zinco, aminoácidos, ácidos graxos e amido (AGAG, 2004). Este desenvolvimento altera o perfil nutricional destes componentes no grão (OSTROWSKI-MEISSNER HT, 1984).

A aflatoxina $\mathrm{B}_{1}$ é o metabólito mais tóxico para os animais domésticos (DIEKMAN \& GREEN, 1992), sendo o fígado o órgão mais afetado, com comprometimento do metabolismo de proteínas, de carboidratos e de lipídios (TERAO \& OHTSUBO, 1991). As aflatoxinas interferem no sistema imunológico de animais, tornando-os mais susceptíveis a patologias virais, bacterianas e parasitárias (DIEKMAN \& GREEN, 1992). Os sinais clínicos de intoxicação por aflatoxinas dependem da idade do animal, da dose e da duração da exposição à toxina (LINDEMANN et al., 1993).

Doses superiores a $200 \mathrm{ug} \mathrm{kg} \mathrm{kg}^{-1}$ provocam anorexia com lesões entéricas (OSWEILER, 1990, MARIN et al., 2002) e reduzem a secreção de enzimas digestivas (AGAG, 2004). Esse quadro patológico possivelmente altere a digestibilidade dos ingredientes e a absorção dos nutrientes, reduzindo o desempenho animal. As pesquisas sobre intoxicação de suínos com aflatoxinas têm sido realizadas para avaliar o desempenho e as alterações hepáticas. Poucas informações estão disponíveis sobre as conseqüências digestivas e metabólicas de aflatoxinas em suínos. Este trabalho teve como objetivo estudar a digestibilidade das dietas e o balanço metabólico de suínos alimentados com dietas contendo $800 \mathrm{ug} \mathrm{kg}^{-1}$ de aflatoxinas.

\section{MATERIAL E MÉTODOS}

O experimento foi realizado no Setor de Suinocultura do Departamento de Zootecnia da Universidade Federal de Santa Maria (UFSM), de setembro a outubro de 2004. Foram utilizados 8 suínos machos castrados, geneticamente homogêneos e meioirmãos paternos, oriundos de cruzamentos industriais, com peso vivo médio inicial de 13 quilogramas. Os animais foram alojados em gaiolas metabólicas, mantidas em ambiente semi-controlado a $22^{\circ} \mathrm{C}$. O delineamento experimental foi o inteiramente casualizado com dois tratamentos (dieta controle e controle $+800 \mathrm{ug} \mathrm{kg}^{-1}$ de aflatoxinas). Cada tratamento teve quatro repetições, sendo o animal a unidade experimental.
As aflatoxinas utilizadas no experimento foram produzidas no Laboratório de Análises Micotoxicológicas (LAMIC) da UFSM. A cepa NRLL 2999 do Aspergillus parasiticus foi produzida por meio de fermentação em arroz parboilizado, de acordo com o método proposto por WEST et al. (1973). A concentração de aflatoxinas foi determinada por meio da análise de cromatografia líquida de alta eficiência (CLAE), com limite de quantificação de 1 ug/kg e coeficiente de recuperação de 85,5\%. A amostra apresentou $83 \%$ de aflatoxina $\mathrm{B}_{1}, 9,5 \%$ de aflatoxina $B_{2}, 4,2 \%$ de aflatoxina $G$ e 3,3\%'de aflatoxina $G_{2}$. O arroz foi adicionado na ração de acordo com a concentração requerida de aflatoxina da dieta. A concentração de aflatoxina do milho utilizado no experimento foi abaixo do limite de quantificação do CLAE, não sendo detectada.

As dietas experimentais (Tabela 1) foram formuladas utilizando o modelo e as recomendações

Tabela 1 - Composições calculadas e analisadas das rações experimentais.

\begin{tabular}{|c|c|c|}
\hline Ingredientes, \% & & Composição \\
\hline Milho & & 67,55 \\
\hline Farelo de soja & & 27,75 \\
\hline Óleo de soja & & 0,70 \\
\hline Premix $^{\mathrm{a}}$ & & 4,00 \\
\hline Total & & 100,00 \\
\hline \multicolumn{3}{|l|}{ Composição calculada } \\
\hline $\begin{array}{l}\text { Energia metabolizável } \\
\mathrm{kcal} / \mathrm{kg}\end{array}$ & & 3.265 \\
\hline Proteína bruta \% & & 20,91 \\
\hline Cálcio \% & & 0,70 \\
\hline Fósforo \% & & 0,59 \\
\hline Lisina \% & & 1,01 \\
\hline Metionina \% & & 0,27 \\
\hline Treonina \% & & 0,63 \\
\hline Composição analisada & Controle & Aflatoxinas, 800ug kg-1 \\
\hline Matéria seca \% & 87,56 & 87,42 \\
\hline Energia bruta kcal/kg & 3.998 & 4.028 \\
\hline Proteína bruta \% & 18,10 & 18,37 \\
\hline Fósforo \% & 0,60 & 0,65 \\
\hline Cálcio \% & 0,90 & 0,94 \\
\hline
\end{tabular}

a Suplemento vitamínico-mineral. Conteúdo por kg de ração: Vit. A, 228.570 UI; Vit. D3, 34.290 UI; Vit. E, 570mg; Vit. K3, 71mg; Vit. B1, 29mg; Vit. B2, 115mg; Vit. B6, 57mg; Vit. B12, 570mcg; Ác. Nicotínico, 715mg; Ác. Pantotênico, 290mg; Biotina, 1,43mg; Ác. Fólico, 17mg; Selênio, 15mg; Colina, 6.860mg; Lisina, 11.430mg; Antioxidante, 17mg; Iodo, 23mg; Cobalto, 13mg; Cobre, 2.500mg; Zinco, 2.200mg; Ferro, $2.000 \mathrm{mg}$; Manganês, $1.100 \mathrm{mg}$.

Ciência Rural, v.36, n.5, set-out, 2006. 
nutricionais descritas no Nutrient Requiriment of Swine (NRC, 1998). O experimento teve duração de 17 dias ( 7 de adaptação dos animais às gaiolas e ao alimento; 10 dias de coleta). As rações foram fornecidas de acordo com o peso metabólico $\left(\mathrm{PV}^{0,60}\right)$. A quantidade diária foi ajustada conforme estimativa do ganho médio diário, considerando um consumo de 2,6 vezes a mantença estimada em 250kcal EM/kg PV ${ }^{0,60}$ (NOBLET et al., 1993). O alimento foi distribuído em três refeições diárias, às 8,13 e 18 horas. Os animais tiveram livre acesso à água.

Foi utilizado o método de coleta total de fezes, sendo o início e o final da coleta determinados pelo aparecimento de fezes marcadas (foram adicionados $1,5 \%$ de $\mathrm{Fe}_{2} \mathrm{O}_{3}$ às dietas). As fezes totais foram coletadas uma vez ao dia, acondicionadas em sacos plásticos e conservadas em congelador a $-10^{\circ} \mathrm{C}$. No final do experimento, as fezes foram homogeneizadas e amostradas $(0,5 \mathrm{~kg})$, secadas em estufa de ventilação forçada $\left(60^{\circ} \mathrm{C}\right.$ por $\left.72 \mathrm{~h}\right)$ e moídas para análises posteriores. A urina excretada foi drenada para baldes plásticos contendo $25 \mathrm{~mL}$ de $\mathrm{HCl} 6 \mathrm{~N}$. A cada 12h, após homogeneização, mediu-se o volume, e uma amostra de $5 \%$ foi retirada e conservada a $4^{\circ} \mathrm{C}$. As análises químicas de fezes e urina foram realizadas segundo metodologia descrita na AOAC (1990). Foram avaliados o coeficiente de digestibilidade aparente da matéria seca (CD MS), o coeficiente de digestibilidade aparente da proteína bruta (CD PB), o consumo de energia (CE), o coeficiente de digestibilidade aparente da energia bruta (CDEB), o coeficiente de metabolização da energia (CME) e o balanço do $\mathrm{N}$ e da energia. Os valores de $\mathrm{CD}_{\mathrm{a}} \mathrm{MS}, \mathrm{CD}_{\mathrm{a}} \mathrm{PB}, \mathrm{CD}_{\mathrm{a}} \mathrm{EB}$ e CME foram determinados de acordo com metodologia proposta por MATTERSON et al. (1965).

Os dados obtidos foram submetidos à análise de variância, incluindo no modelo os efeitos das aflatoxinas. As análises estatísticas foram realizadas por meio do SAS versão 8.0 (SAS, 2000).

\section{RESULTADOS E DISCUSSÃO}

Os resultados dos coeficientes de digestibilidade da matéria seca, da proteína bruta, da energia bruta e da metabolização da energia são apresentados na tabela 2. A presença de aflatoxinas na dieta não afetou $(\mathrm{P}>0,05)$ os coeficientes de digestibilidade da matéria seca, da proteína e da energia bruta. O coeficiente de metabolização da energia bruta diminuiu 6\% $(\mathrm{P}<0,05)$ nos animais alimentados com dieta com aflatoxinas.

As aflatoxinas são componentes lipossolúveis facilmente absorvidos no trato gastrintestinal e metabolizados no fígado (DIEKMAN \& GREEN, 1992). No sistema digestivo, as aflatoxinas causam lesões nos enterócitos, podendo, em doses elevadas, provocar hemorragias entéricas (AGAG, 2004). As lesões nos enterócitos estão relacionadas ao nível de aflatoxinas na dieta e à idade dos animais, com maior suscetibilidade de ocorrerem em animais jovens (PIER, 1992; LAWLOR \& LYNCH, 2001). Asensibilidade de leitões às aflatoxinas pode ser reduzida pelos níveis elevados de proteína (>20\%) e de aminoácidos da dieta (COFFEY et al., 1989). Em monogástricos intoxicados com aflatoxinas, é comum ocorrer alterações na atividade de enzimas relacionadas à digestão de carboidratos e lipídios (AGAG, 2004). As alterações dos enterócitos e a secreção enzimática em animais intoxicados por aflatoxinas podem modificar a digestibilidade dos ingredientes, fato não observado em nosso experimento. A alimentação dos animais com aflatoxinas por um período inferior a dez dias pode não ter sido suficiente para provocar alterações agudas no trato gastrintestinal. O efeito da toxina depende do nível de contaminação e do período de ingestão (LINDEMANN et al., 1993).

As aflatoxinas afetam principalmente o fígado, alterando o metabolismo de proteínas, de carboidratos e de lipídios (TERAO \& OHTSUBO, 1991). Em doses tóxicas, as aflatoxinas causam uma

Tabela 2 - Digestibilidade aparente e metabolização da energia bruta de dietas para leitões com ou sem adição de $800 u g$ kg ${ }^{-1}$ de aflatoxinas.

\begin{tabular}{|c|c|c|c|c|}
\hline \multirow{2}{*}{ Variáveis } & \multicolumn{2}{|c|}{ Tratamentos } & \multirow{2}{*}{ Epr $^{1}$} & \multirow{2}{*}{$\mathrm{P}^{2}$} \\
\hline & Controle & Aflatoxinas, 800ug kg-1 & & \\
\hline \multicolumn{5}{|l|}{ Coeficiente de digestibilidade } \\
\hline Matéria seca \% & 82,91 & 81,42 & 1,25 & 0,58 \\
\hline Proteína bruta \% & 77,77 & 76,97 & 1,52 & 0,81 \\
\hline Energia bruta \% & 82,27 & 80,73 & 1,43 & 0,50 \\
\hline Coef. metabolização da energia bruta ${ }^{3}$ & 82,88 & 78,43 & 1,32 & 0,05 \\
\hline
\end{tabular}

${ }^{1}$ Erro padrão residual; ${ }^{2}$ nível de 5\% de significância; ${ }^{3}$ energia ingerida utilizada como covariável.

Ciência Rural, v.36, n.5, set-out, 2006. 
degeneração gordurosa hepática pelo aumento de síntese e pela diminuição na oxidação/exportação de ácidos graxos (KIESSLING, 1986). As enzimas glicogênicas e a gliconeogênese são inibidas no metabolismo dos carboidratos (MCLEAN \& DUTTON, 1995). Essas alterações metabólicas aumentam a oxidação de glicose, alterando o metabolismo energético (LEHNINGER et al., 1995). Esses fatores podem ter contribuído para a menor eficiência na utilização da energia nos animais alimentados com aflatoxinas.

Os resultados do balanço do $\mathrm{N}$ são apresentados na tabela 3. A ingestão, a absorção, a excreção fecal e a retenção de $\mathrm{N}$ não foram influenciadas $(\mathrm{P}>0,05)$ pelo consumo de aflatoxinas. $\mathrm{O} \mathrm{N}$ urinário e retido em função do absorvido foi afetado $(\mathrm{P}<0,05)$ pela adição de aflatoxinas na dieta. A excreção de $\mathrm{N}$ urinário aumentou 52\% e a retenção relativa à absorção diminui em 31\% nos animais alimentados com dietas contendo aflatoxinas. Esses efeitos são provocados por metabólitos das aflatoxinas que se complexam com várias proteínas como a albumina, que é transportadora de aminoácidos (VIVIERS \& SCHABORT, 1985). A menor retenção de $\mathrm{N}$, contudo, pode estar relacionada à ligação dos metabólitos da aflatoxina $\mathrm{B}_{1}$ ao RNA e ao DNA, bloqueando a transcrição e interferindo na síntese protéica (PIER, 1992).

A redução na síntese protéica e de transporte de aminoácidos em animais intoxicados por aflatoxinas pode ser avaliada por meio de indicadores séricos (HARVEY et al., 1988b; LINDEMANN et al., 1993), principalmente de uréia plasmática, que apresenta correlação com o balanço do N (HENNIG et al., 1982). Em leitões alimentados com 280ug kg-1 de aflatoxinas na dieta, os parâmetros sanguíneos não foram alterados (MARIN et al., 2002). Em doses mais elevadas (800ug $\mathrm{kg}^{-1}$ ), houve redução na proteína total, na uréia plasmática e na albumina (LINDEMANN et al., 1993). Os autores retrocitados demonstraram que níveis elevados de aflatoxinas em dietas para leitões alteram os parâmetros sanguíneos relacionados à síntese protéica, podendo modificar o balanço do nitrogênio.

Os resultados da ingestão, das excreções fecal e urinária da energia e da energia metabolizável das dietas são apresentados na tabela 4. A dieta com aflatoxinas não influenciou $(\mathrm{P}>0,05)$ a ingestão e a excreção fecal de energia dos suínos. Entretanto, a excreção urinária de energia foi afetada $(\mathrm{P}<0,05)$ pelo consumo da dieta com aflatoxinas. A alimentação com 800ug kg ${ }^{-1}$ de aflatoxinas na dieta aumentou em 52\% a excreção de energia em relação ao grupo controle. A energia metabolizável das dietas não foi influenciada $(\mathrm{P}>0,05)$ pela adição de aflatoxinas. A excreção mais elevada de energia na urina está relacionada à modificação do metabolismo protéico pelos metabólitos das aflatoxinas, ocasionando deficiência energética (MCLEAN \& DUTTON, 1995). Neste processo, o mecanismo homeostático de regulação do suíno provavelmente reagiu desaminando aminoácidos em excesso, com utilização do carbono como fonte de energia (KRYUKOV et al., 1992). A maior excreção de energia observada na urina, em nosso estudo, pode estar relacionada ao gasto energético para desaminação dos aminoácidos.

A intoxicação por aflatoxinas em doses elevadas altera o metabolismo energético e protéico dos animais, cujas intoxicações, mesmo subclínicas, podem refletir no desempenho zootécnico. Essa condição sugere um monitoramento micotoxocológico do milho da colheita ao armazenamento.

\section{CONCLUSÕES}

Os coeficientes de digestibilidade da matéria seca, da proteína e da energia bruta não são alterados em dietas contendo 800ug $\mathrm{g}^{-1}$ de aflatoxinas; contudo, o coeficiente de metabolização da energia é reduzido. A ingestão de 800ug kg-1 de aflatoxinas afeta o balanço de $\mathrm{N}$ de leitões, aumentando a excreção urinária e diminuindo a retenção relativa. A alimentação de leitões

Tabela 3 - Balanço do nitrogênio de leitões alimentados com dietas com ou sem adição de $800 \mathrm{ug} \mathrm{kg}^{-1}$ de aflatoxinas.

\begin{tabular}{|c|c|c|c|c|}
\hline \multirow{2}{*}{ Variáveis } & \multicolumn{2}{|c|}{ Tratamentos } & \multirow{2}{*}{$\operatorname{Epr}^{1}$} & \multirow{2}{*}{$\mathrm{P}^{2}$} \\
\hline & Controle & Aflatoxinas, 800ug kg ${ }^{-1}$ & & \\
\hline \multicolumn{5}{|l|}{ Nitrogênio } \\
\hline Ingerido g/dia & 22,73 & 26,53 & 2,33 & 0,23 \\
\hline Absorvido $^{3}$ g/dia & 17,62 & 20,52 & 2,71 & 0,81 \\
\hline Fecal g/dia & 5,10 & 6,01 & 0,87 & 0,43 \\
\hline Urinário g/dia & 4,84 & 10,25 & 1,16 & 0,01 \\
\hline Retido $^{4}$ g/dia & 12,79 & 10,27 & 1,66 & 0,26 \\
\hline Retido/Absorvido \% & 72,37 & 49,84 & 5,08 & 0,01 \\
\hline
\end{tabular}

${ }^{1}$ Erro padrão residual; ${ }^{2}$ nível de 5\% de significância, ${ }^{3} \mathrm{~N}$ absorvido: $\mathrm{N}$ ingerido - $\mathrm{N}$ fecal; ${ }^{4} \mathrm{~N}$ Retido: $\mathrm{N}$ ingerido - ( $\mathrm{N}$ fecal + $\mathrm{N}$ urinário). 
Tabela 4 - Ingestão, excreção fecal e urinária e energia metabolizável de dietas para leitões com ou sem adição de 800ug kg ${ }^{-1}$ de aflatoxinas.

\begin{tabular}{|c|c|c|c|c|}
\hline \multirow{2}{*}{ Variáveis } & \multicolumn{2}{|c|}{ Tratamentos } & \multirow{2}{*}{ Epr $^{1}$} & \multirow{2}{*}{$\mathrm{P}^{2}$} \\
\hline & Controle & Aflatoxinas, 800ug kg-1 & & \\
\hline \multicolumn{5}{|l|}{ Energia bruta } \\
\hline Ingerida kcal/dia & 3.746 & 3.647 & 957,23 & 0,71 \\
\hline Fecal kcal /dia & 512 & 507 & 195,39 & 0,92 \\
\hline Urinária kcal/dia & 44 & 94 & 6,73 & 0,02 \\
\hline \multicolumn{5}{|c|}{ Energia Metabolizável } \\
\hline Ingerida $^{3} \mathrm{kcal} / \mathrm{dia}$ & 3.140 & 3.096 & 54,55 & 0,68 \\
\hline
\end{tabular}

${ }^{1}$ Erro padrão residual; ${ }^{2}$ nível de 5\% de significância; ${ }^{3}$ EM ingerida: EB ingerida - (EB fecal + EB urinária).

com 800ug $\mathrm{kg}^{-1}$ de aflatoxinas aumenta a excreção urinária de energia, sem interferir nas demais variáveis do balanço da energia.

\section{AGRADECIMENTOS}

Os autores agradecem o Conselho Nacional de Desenvolvimento Científico e Tecnológico (CNPq), pela concessão de bolsa ao mestrando do Programa de Pós-graduação em Zootecnia (UFSM) Luciano Hauschild; à Fundação de Amparo à Pesquisa do Estado do Rio Grande do Sul (FAPERGS) pela concessão de bolsa de iniciação científica ao graduando em Zootecnia (UFSM) Marco Antônio Kunrath ao; Laboratório de Análises Micotoxicológicas (LAMIC), pela realização das análises micotoxicológicas e à Adisseo Brasil, pelas análises químicas dos ingredientes.

\section{REFERÊNCIAS}

AGAG, B.I. Mycotoxins in foods and feeds 1-aflatoxins. Assiut University Bulletin for Environmental Researches. v.7, p.36, 2004. Acesso em 28 dez. 2005. Online. Disponível na Internet http://www.aun.edu.eg/env_enc/env\%20mar/1-8.PDF.

AGrianuAl. Anuário estatístico. São Paulo, SP: FNP Consultoria \& Comércio, 2005. 520p.

AOAC. Official methods of analysis. 15.ed. Arlington, 1990. 1117p.

COFFEY, M.T. et al. Influence of dietary protein, fat or amino acids on the response of weanling swine to aflatoxin B1. Journal of Animal Science, v.67, p.465, 1989.

LEHNinger, A. L. et al. Princípios de bioquímica. 2.ed. São Paulo: Sarvier, 1995. 839p.

DIEKMAN, M.A.; GREEN, M.L. Mycotoxins and reproduction in domestic livestock. Journal Animal Science, v.70, p.1615-1627, 1992.

DILKIN, P. et al. Toxicological effects of chronic low doses of aflatoxin B1 and fumonisin B1-containing Fusarium moniliforme culture material in weaned piglets. Food and Chemical Toxicology, v.41, p.1345-1353, 2003.

HARVEY, R.B. et al. Suppression of serum iron-binding capacity and bone marrow cellularity in pigs fed aflatoxin. Bulletin of
Environment Contamination Toxicology, v.40, p.573-583, $1988 b$.

HENNIG, U. et al. Effect of graded protein supply at highenergy level on the fattening performance and the retention and utilization of feed energy, protein and amino acids by female fattening swine. 3 . $\mathrm{N}$ retention and $\mathrm{N}$ and lysine metabolism determined by $\mathrm{N}$ balance and $\mathrm{N}$ analysis of the carcasses. Archiv Tierernährung, v.32, p.637-649, 1982.

HENNING, M.R.; DICK, T. Incidence and abundance of mycotoxins in corn in Rio Grande do Sul, Brazil. Food Additives and Contaminants, v.12, n.5, p.677-681, 1995.

JACOBSEN, B.J. et al. Mycotoxins and mycotoxicosis. Alabama: University of Aubern, 1993. (Circular ANR- 767).

KIESSLING, K.H. Biochemical mechanisms of action of mycotoxins. Pure \& Applied Chemistry, v.58, p.327-338, 1986.

KRYUKOV, V.S. et al. Effect of aflatoxin on protein utilization by broilers. Pticeprvodsvo, v.3, p.13-15, 1992.

LAWLOR, P.G.; LYNCH, P.B. Mycotoxins in pig feeds. 2: clinical aspects. Irish Veterinarian Journal, v.54, n.4, p.172176, 2001.

LINDEMANN, M.D. et al. Potential ameliorators of aflatoxicosis in weanling/growing swine. Journal Animal Science, v.71, p.171-178, 1993.

MARIN, D.E. et al. Changes in performance, blood parameters, humoral and cellular immune responses in weanling piglets exposed to low doses of aflatoxin. Journal Animal Science, v.80, p.1250-1257, 2002.

MATTERSON, L.D. et al. The metabolizable energy of feed ingredients for chickens. Research Report, v.7, p.3-11, 1965.

MCLEAN, M.; DUTTON, M.F. Cellular interactions and metabolism of aflatoxin: An update. Pharmacology \& Therapeutics, v.65, p.163-192, 1995.

NOBLET, J. et al. Metabolic utilization of dietary energy and nutrients for maintenance energy requirements in sows: basis for a net energy system. Britsh Journal Nutrition, v.70, p.407-419, 1993.

NRC. Nutrient requirements of swine. 10.ed. Washington: National Academy of Sciences, 1998. 189p. 
OSTROWSKI-MEISSNER H.T. Effect of contamination of foods by Aspergillus flavus on the nutritive value of protein. Journal of the Science of Food and Agriculture, v.35, p.47-48, 1984

OSWEILER, G.D. Mycotoxins and livestock: what role do fungal toxins play in illness and production losses? Veterinary Medicine, v.85, p.89-94, 1990.

PEDROSA, A.V. B.; DEZEN, R.B. O milho: características do mercado e perspectivas. Preços agricolas, v.55, p.1-4, 1991

PIER, A.C. Major biological consequences of aflatoxicosis in animal production. Journal Animal Science, v.70, p.39643967, 1992

SAS INSTITUTE. SAS user's guide: statistical analysis system, Release 8.0. Cary, NC, 2000. 544p.
SINDIRAÇÕES. Demanda de macronutrientes. Acesso em 20 dez. 2005. Online. Disponível em http:// www.sindiracoes.org.br.

TERAO, K.; OHTSUBO, K. Biological activities of mycotoxins: field end experimental mycotoxicoses. In: SMITH, J.E.; HENDERSON, R.S. Mycotoxins and animal foods. Boca Raton: CRC, 1991 . Cap.21. p.455-488.

VIVIERS, J.; SCHABORT, J.C. AFB1 alters protein phosphorylation in rat livers. Biochemical and Biophysical Research Communication, v.129, p.342-349, 1985.

WEST, S. et al. Increased yield of aflatoxin by incremental increases of temperature. Application Environment Microbiology, v.25, p.1018-1019, 1973. 